\title{
OPTIMIZATION METHODS OF THE PAVEMENT MANAGEMENT SYSTEM OF BUDAPEST
}

\author{
Kornel ALMASSY ${ }^{\circledR 1}$, Gábor PUSZTAI ${ }^{1}$, László GÁSPÁR ${ }^{\circledR 2}$, János LÓGÓ®3* \\ ${ }^{1}$ Budapest Közút Zrt, Budapest, Hungary \\ ${ }^{2}$ Research Institute of Transportation, Budapest, Hungary \\ ${ }^{3}$ Department of Structural Mechanics and Department of Highway and Railway Engineering, \\ Faculty of Civil Engineering, Budapest University of Technology and Economics, Budapest, Hungary
}

Received 18 April 2019; accepted 16 May 2019

\begin{abstract}
A modern Pavement Management System (PMS) should be essential for maintenance a metropolitan urban road network. Municipality of Budapest has developed own management system for their road pavement operation. To an efficient outcome the newest methods are used for the data collecting with the most innovated geo-informatics solutions, which are help us in our multi criteria decision making process. We present a degradation model which useful for the prediction of the roughness, yielding surface condition of the pavement in the future. After the whole data evaluation we give accurate information about the general characterization of the permanent road network conditions. Our paper shows that in all modern asset management system based on multi criteria decision making processes, which contain single or multi objective optimization methods. The PMS based on the available-technical and financial data and its optimization process provides a pavement renovation offer for each road in Budapest transportation network and finally the paper presents how can we ranking the invention list from our optimization process.
\end{abstract}

Keywords: Pavement Management System (PMS), geo-database, data collecting, evaluation, multi criteria optimization, intervention, renovation cost.

\section{Introduction}

The road structure is one of the most important assets of a city even more if it is a capital, which is has direct impact on the life quality and conditions of the local population. Both the owner and the operator organisation are responsible for preservation of the consistency and quality of this important asset. Calculating the maintenance cost additional extra factors have to be also considered like extra cost of traffic restrictions or too late repairing cost. The maintenance of Budapest's road network is a very complex task where the most innovative technical solutions have to be used to optimize or decrease the total costs. The usual goal of all operator organizations is to use effectively the limited resources. The road operator company of Budapest is called Budapest Roads Ltd. started to develop a Pavement Management System (PMS) in 2011 (Bakó, Gáspár, \& Kovács, 2012; BKK Közút Zrt, 2015).

PMS is a "set of defined procedures for collecting, analyzing, maintaining, and reporting pavement data, to assist the decision makers in finding optimum strategies for maintaining pavements in serviceable condition over a given period of time for the least cost" (Vittilo, 2013). Property management requires up-to-date and accurate information about the assets and support for the decision making processes with scientific model based analytics.

"The Pavement Management System (PMS) collects all such activities, that supports the public traffic related infrastructure management decision making processes based on objective technical aspects applied by structured parameter analysts and evaluation that aids reasonable allocate the available limited financial and human resource" (Gáspár, 2003).

Currently the most innovated technology is available for the data collecting which is one of the most important components of the PMS. The collected accurate and detailed data are the safe basis for finding the optimum intervention mode (Gáspár, 2017). The design of city road pavement reconstruction process is a multiple criteria optimization and decision support task. The purpose

${ }^{\star}$ Corresponding author. E-mail: logo@ep-mech.me.bme.hu 
of the Pavement Management Systems (PMS) is to help the decision makers to find the best possible allocation of available resources with technical data and analyzes. Several complex mechanical models have been developed for modeling road degradation and find the optimal reconstruction processes, but network-level analysis is required for simplifying the complex calculations.

This paper shows how the data collecting and computing work in a modern PMS and also present the optimization method of the Budapest' Pavement Management System. The article highlights three important areas of the PMS model. First, we collect the data and calculation methods of the present value of status data (Section 1). Second, we show the estimation process of the optimal intervention based on the collected data (Section 2), and the intervention matrix (Section 3). Finally third we present how to rank the planned interventions (Sections 4 and 5).

\section{Data collecting and degradation calculating for Budapest PMS}

Budapest's road operator company has been collecting data for PMS analytics for several years. In recent years pavement management systems have experienced a significant evolution in modules of increased cost analysis, degradation calculating and forecasting.

\subsection{Data collecting}

Achieving this goal development of RODIS (ROad Data Information System) has started in 2013 that provides very high-resolution 3D data with $100 \%$ coverage of all public roads of Budapest. Furthermore such solution produces state-of-the-art, accurate, up-to-date and reliable data. RODIS applies LIDAR technology (Lefsky et al., 1999) using Mobile Laser Scanning (RIEGL VMX-450) solution with ground photogrammetry (Vosselman \& Maas, 2010). The result of the survey is 3D "image" of the field, so called point cloud that supports more economic city planning and construction quality check and also very high accuracy analyst like PMS can be applied as Sun, Xu, Hoegner, and Stilla (2018) wrote.

The main task of RODIS (VMX-450 + VZ-400 scanners, post-processing, vectorization and data management software package) is to produce the full $3 \mathrm{D}$ road vector geo-database of the city including all road-related features that can be mapped from the scanned data.

It is necessary to have good enough and acceptable amount of source data - exclude from 3D GIS data - to implement a PMS (Rusu, Taut, \& Jecan, 2015). It was a big work in terms of Budapest to get all the necessary data city-wise from the $5458 \mathrm{~km}$ length road network until the first PMS process could start.

Input data comes from various sources that have different accuracy and resolution - data harmonisation is needed. All the data are linked to the in-house defined linear reference system. Sections were created in the way to align the biggest resolution data that is the surface condition level maintained by utility manager:
- Applied road axes are the Budapest Roads's own linear network.

- Carrying capacity yielding data comes from Lacriox carrying capacity measurement vehicle. The measurement methodology is similar to man-portable methodology, the difference is the way of the operational solution - at the vehicle the measuring units are mounted on an automatic surveying vehicle that during its slow motion $(3-5 \mathrm{~km} / \mathrm{h})$ measures the pavement yield in every $4 \mathrm{~m}$ (Markó, Primusz, \& Péterfalvi, 2013; Markó, Primusz, Péterfalvi, \& Tóth, 2015).

- International Roughness Index (IRI) in PMS of Budapest Roads was processed by in-house algorithm based on MLS point cloud surface model. The point cloud was provided by RODIS. Applied scientific model like autonomous robot (Chang, Su, Huang, Kang, \& Hsieh, 2009) was used by algorithm of World Bank, the values were re-synchronized to city environment (Almássy \& Németh, 2014).

- Surface condition data was provided by utility managers. These experts provides such complex information based on their professional experience that the result is weighted by the traffic level, level of usage and other hardly measurable parameters of a certain road section.

- Traffic information was provided by the Budapest's Common Traffic Model, (complex development and modelling from Budapest roads and transportation habitat from 2014) that provides common information for about typical traffic of each road sections and also gives data of vehicle types in the traffic.

- Last reconstruction year comes for Company's road maintenance department inventory.

- RODIS provided the survey grade level 3D MLS point cloud for the whole surface of public roads and pedestrian paths. Based on this source data 3D traffic vector base map were created (that is updated every year). This 3D GIS data provides all necessary information about road width, surface and length of curbs.

- Road layer structure data comes from two different sources. One and most important and accurate is the sample drilling information. The other less accurate source is the photos took by utility managers during pavement wrecking and they also give information about the cracking of the surface.

- Underground data comes from National Geology Institute using their geological base maps.

\subsection{Enough and proper pavement condition data from failing/degradation curves}

The aim of failing/degradation curve is to predict later expected values based on the currently known condition values. For the definition of degradation functions we had support from study by Ambrus (2015) as you can see at Table 1. There was available exact road structure (asphalt thickness, base layer type) only on part of the road net- 

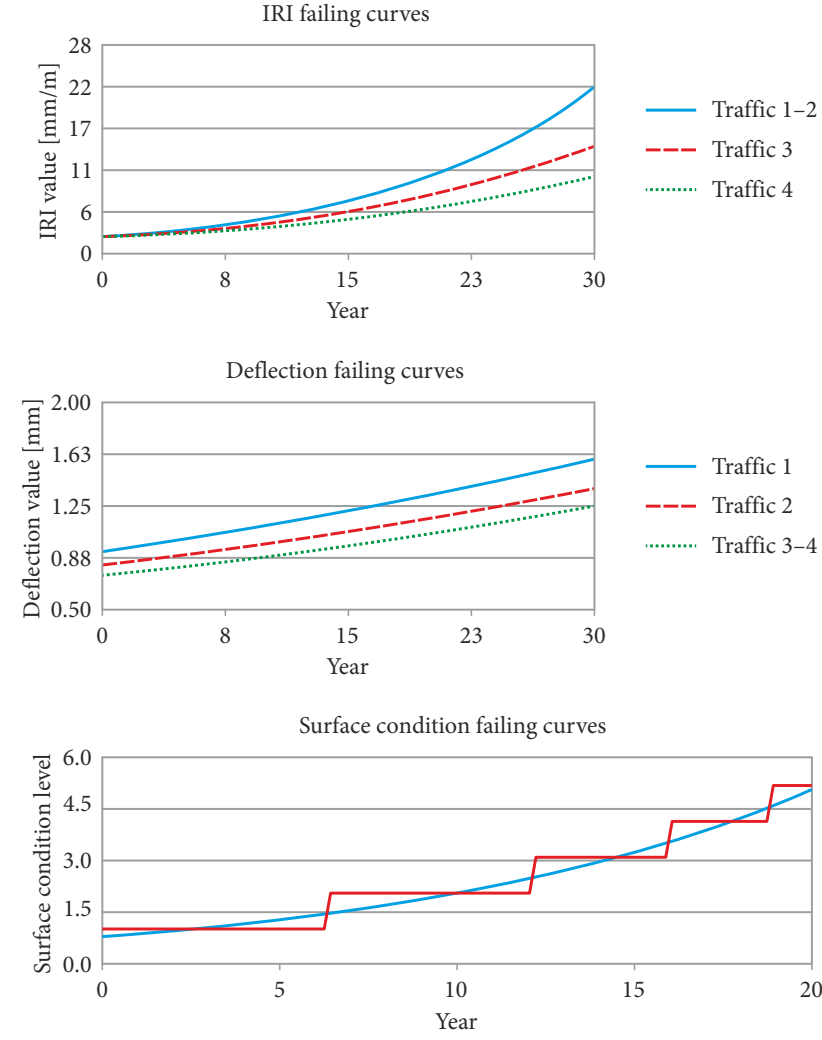

Figure 1. Failing/degradation curves

(Almássy, Dávid, \& Pusztai, 2018)

work when the study was made. It was not possible to examine by categories the degradation tendencies due to limited data, since too much unreliable results were calculated. There was also an issue that no degradation data was available for a certain road section because of missing long-term etalon section measurements. Furthermore traffic size was available for the entire road network from Common Traffic Model and also road ages were available. Due to above situation a simplified model was applied.

Categories of roads were defined based on traffic size, and we defined at the Figure 1 the failing/ degradation curves for same road category but different road age (Németh \& Pusztai, 2016). Applying the curbs first - if measured data is available - curve should be aligned to measured data vertically then future or actual condition value can be read.

The following Table 1 shows how the failing/degradation curves values are calculated based on traffic size (where $x$ equal to years gone since last reconstruction year of given road section $x$ ).

\section{Optimization in decision making in infrastructure asset management}

Nowadays any infrastructure maintenance is unthinkable without asset management, which helps the decision making and makers. And these kind of engineering problems have been resolved by multi criteria optimization methods (Lógó, 1988; Lógó, Kacianauskas, Bernau, \& Vásárhelyi, 1989).
Table 1. Calculation of the different failing curves based on traffic size (Németh \& Pusztai, 2016)

\begin{tabular}{|c|c|c|}
\hline Type & Traffic category & Function \\
\hline \multirow{4}{*}{ IRI } & 0-300 ESAL/day & \multirow{2}{*}{$f(x)=2.3 e^{0.075 x}$} \\
\hline & 301-900 ESAL/day & \\
\hline & 901-3000 ESAL/day & $f(x)=2.2 e^{0.063 x}$ \\
\hline & 3000- ESAL/day & $f(x)=2 e^{0.055 x}$ \\
\hline \multirow{4}{*}{ Deflection } & 0-300 ESAL/day & $g(x)=0.9314 e^{0.0179 x}$ \\
\hline & 301-900 ESAL/day & $g(x)=0.8289 e^{0.0172 x}$ \\
\hline & 901-3000 ESAL/day & \multirow{2}{*}{$g(x)=0.7543 e^{0.0166 x}$} \\
\hline & 3000- ESAL/day & \\
\hline \multirow{4}{*}{$\begin{array}{l}\text { Surface } \\
\text { condition }\end{array}$} & 0-300 ESAL/day & \multirow{4}{*}{$h(x)=0.8186 e^{0.0905 x}$} \\
\hline & 301-900 ESAL/day & \\
\hline & 901-3000 ESAL/day & \\
\hline & 3000- ESAL/day & \\
\hline
\end{tabular}

Chen and Bai (2019) perfectly summarize the publications on optimization in decision making in infrastructure asset management. They collected 337 articles from different parts of the world. Decision support articles focus on network-level analysis. Since 2000, project-level decisionmaking support has become more and more frequent.

Optimization can be generally classified into two types, as follows: single-objective optimization and multiobjective optimization (Hillier \& Lieberman, 2005). Their relationship and targeted solutions are shown in Figure 2.

Single-objective optimization optimizes only one optimization objective subject to optimization constraints. It aims at the optimal solution that produces the best value on the objective and satisfies all the constraints. Multiobjective optimization optimizes multiple optimization objectives subject to optimization constraints. It aims at Pareto solutions, each producing the best objective values that cannot be improved without worsening the value of another objective. Additionally, all the Pareto solutions satisfy all the constraints. The method of weighting objectives is well known approach to vector optimization problems and other engineering optimization methods. The basis of

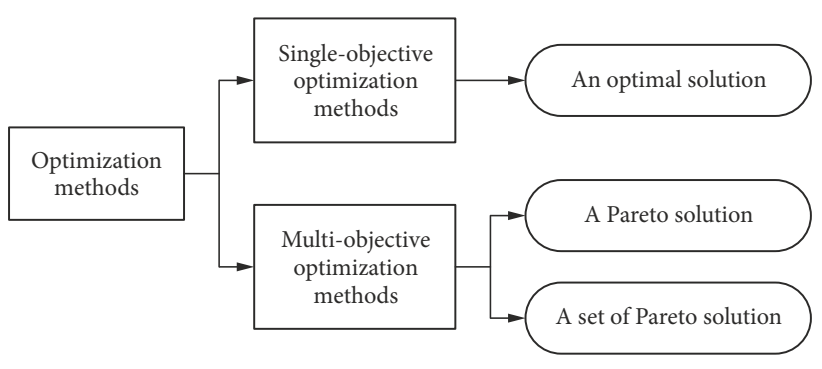

Figure 2. Types of optimization methods and their targeted solutions 
this method is summing all the objective functions using different weights for each. So the scalar problem has the following objective Eqn (1) (Lógó \& Kaliszky, 2003; Lógó \& Vásárhelyi, 1988):

$$
F(\mathbf{x})=\sum_{i=1}^{m} \lambda_{i} f_{i}(\mathbf{x})
$$

where $\lambda_{i} \geq 0$ are the weighting coefficients. It is usually assumed that $\sum_{i=1}^{m} \lambda_{i}=1$.

A multi-objective optimization problem always has more than one existing Pareto solution. Some multi-objective optimization methods can identify a set of Pareto solutions, while others only identify one Pareto solution, which is the result of a post optimization event, based on the decision makers' preference (Chen \& Bai, 2019).

Optimization is a useful tool for decision making in infrastructure asset management and great achievements are gained by the articles. Its significance is widely admitted by researchers and practitioners. However, with the development of infrastructure asset management, decision making becomes more complex. Firstly, an essential issue in infrastructure asset management is to keep the infrastructure condition at an acceptable level. This requires an accurate model and prediction of the infrastructure deterioration, while the deterioration is affected by the chang- ing environment and filled with uncertainties. Hence the prediction of infrastructure condition over the long-term is still a critical topic. Additionally, each decision making problem is unique and none of the optimization methods is a panacea. All of the algorithms have their strengths and limitations. Hence, the selection of a proper optimization algorithm depends on the addressed problem (Chen \& Bai, 2019).

\subsection{The flow chart of the PMS of Budapest Roads}

There are three levels in PMS analysis. The goal of the network-level analysis is to support short and medium term road rehabilitation programs. In the analysis, the optimal intervention technology is searched for the road sections and the expected costs are calculated. Based on the suggestions for intervention, an optimal list of interventions is selected using several criteria. It can be considered as a multi-criteria optimization analysis, but in practice a multivariate ranking has been completed. The strategic level analysis aims to support the development of a longterm strategy. In the phase we analyze the financial consequences of the general objectives (e.g. keeping the condition level, slight deterioration). We are also analyzing the effects that we can expect in the long run while retaining the current budget. The project level analysis supports the design and the implementation of a section. We provide

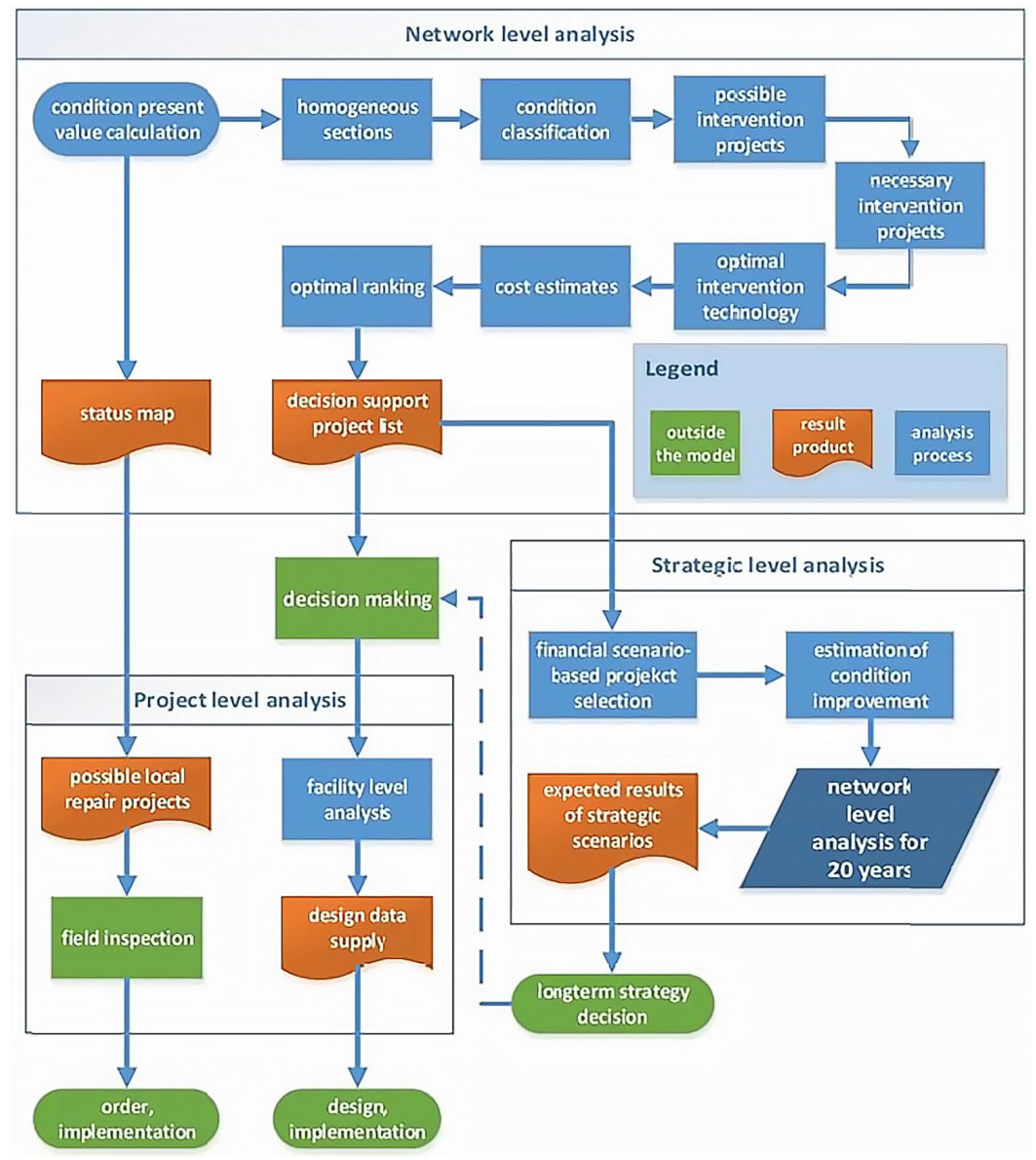

Figure 3. Flowchart of the PMS of Budapest 
data services for the design of a designated road section, and we also recommend local repair projects. Following Figure 3 shows the flow chart of our PMS.

\section{Optimal intervention in Budapest PMS Model}

The intervention model of PMS system is based on a general exponential degradation model. The theoretical models of the literature consider the aim to determine the optimal time of intervention. Moving forward over time on the exponential curve, the increasing degradation means more and more intervention costs. The optimum intervention period means that intervening on a given period, but the total cost of interventions is minimal in the long run (while the condition is constant). Optimal search is complicated by the fact that the costs are not merely the direct costs of the renovation. Costs include maintenance and restoration costs that are constantly increasing depending on the degree of degradation, as well as road user costs.

In the PMS of Budapest Roads, the theoretical process detailed above was reversed. In network-level analyses, we are looking for the right method of intervention for the road sections with different parameters at that time.

Optimum intervention is influenced by the state of the road section, the size and distribution of the traffic, and the current pavement structure. In the practical solution, three intervention parameters were defined for the three state parameters, from which an intervention matrix was formed (Figure 4).

\section{Optimal ranking}

The intervention costs are also determined on the basis of optimal intervention for each road section. The optimal allocation of the available budgets was also determined on the basis of the intervention costs. For optimal distribution, the current model uses a multi-variable rankings method. The bases for the ranking of the individual projects are the economic, traffic and pavement status aspects, as well as on the goals produced by the aspects. An indicator can be assigned to each goal, on the basis of which the interventions can be sorted. All interventions are graded on a 10 -point scale, where 10 is the best. Then the relationship between the three goals must be determined, that means they are summed by weight. Then, the relationship between the indicators must be determined. The three indicators are weighted together. In many cases, the importance of the goals is no longer a technical issue, and in this case several types of weighting should be considered.

The first goal is to repair as many surface defects as possible. The number of potholes on the surface that was repaired by Budapest Roads over the past three years is proportional to the entire surface of the section. The ratio thus obtained is linearly graded between 0 and 0.05 to give a value of 0 to $10($ Eqn (2)).

$$
G_{t}= \begin{cases}0, & \text { if } \quad g_{c}<0 ; \\ \frac{g_{c}}{0.005}, & \text { if } 0 \leq g_{c} \leq 0.05 \\ G_{c}=10, & \text { if } \quad \text { if } g_{c}>0.05\end{cases}
$$

where

$$
g_{c}=\frac{\sum_{y=1}^{3} \sum_{i=1}^{n} A_{p i}}{A_{r}},
$$

where: $g_{c}$ - status goal index; $G_{c}$ - status goal mark; $y$ - the number of the examined years (now $1-3$ ); $i$ - current pothole number (between 1 to $n$ ); $n$ - the number of repaired potholes within the examined year in the given section; $A_{p i}$ - surfaces of repaired potholes $\left(\mathrm{m}^{2}\right) ; A_{r}$ - surfaces of the whole road section $\left(\mathrm{m}^{2}\right)$.

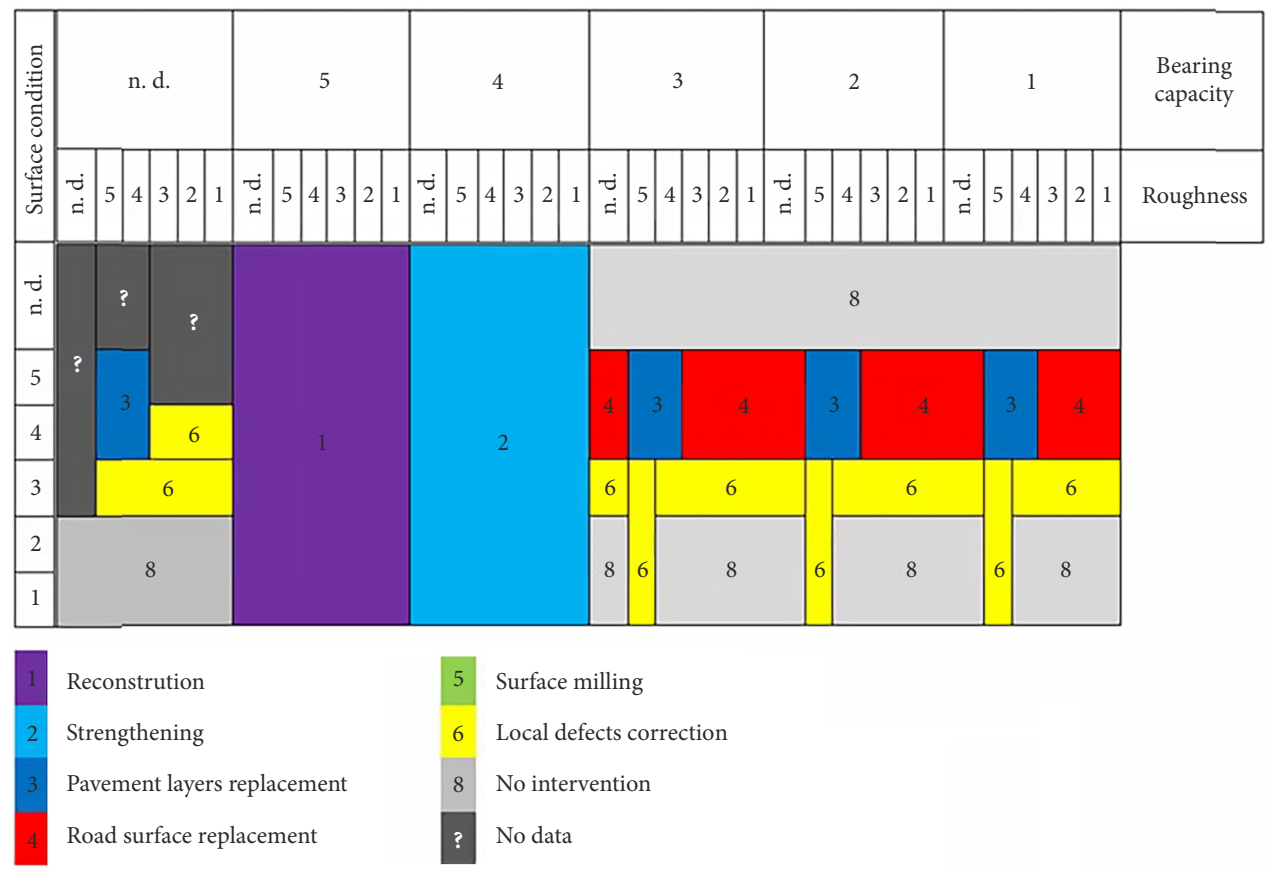

Figure 4. Intervention matrix (Almássy, Dávid, \& Pusztai, 2018) 
The second goal is to minimize the future costs of untreated interventions. If an intervention is not done at this time, then after 5 or 10 years, due to the degradation, it is expected that a higher cost intervention will be required. By comparing current costs and the expected costs of intervention after 5 or 10 years, an appropriate measure can be assigned to each stage. The additional costs over 5 years were taken into account with a weight of 0.6 and an additional cost of 10 for 0.4 . The ratio thus obtained is linearly graded between 0 and 40000 to give a value of 0 to 10 (Eqn (3)):

$$
G_{e}=\left\{\begin{array}{cll}
0, & \text { if } & g_{e}<0 \\
\frac{g_{e}}{4000,}, & \text { if } & 0 \leq g_{e} \leq 40000 \\
10, & \text { if } & \text { if } g_{e}>40000,
\end{array}\right.
$$

where

$$
g_{e}=\frac{0.6 \times\left(C_{5}-C_{0}\right)+0.4 \times\left(C_{10}-C_{0}\right)}{A_{r}},
$$

where: $g_{e}$ - economic goal index; $G_{e}$ - economic goal mark; $C_{0}$ - expected intervention cost currently (HUF); $C_{5}$ - expected intervention cost 5 years later (HUF); $C_{10}$ expected intervention cost 10 years later (HUF).

The third goal is that interventions improve travel comfort for as many passengers as possible. The best indicator of this is the Average Daily Traffic passing through each section. Average daily traffic data is derived from the Standard Traffic Model of BKK data, with the weighted amount of average daily vehicle numbers for each traffic class. The ratio thus obtained is linearly graded between 0 and 50000 to give a value of 0 to 10 (Eqn (4)):

$$
G_{t}=\left\{\begin{array}{cll}
0, & \text { if } & g_{t}<0 ; \\
\frac{g_{t}}{5000}, & \text { if } & 0 \leq g_{t} \leq 50000 ; \\
10, & \text { if } & \text { if } g_{t}>50000,
\end{array}\right.
$$

where

$$
g_{t}=\sum_{i=1}^{n} F_{n} \times e_{n},
$$

where: $g_{t}$ - traffic goal index; $G_{t}$ - traffic goal mark; $i$ traffic class number (between 1 to $n$ ); $F_{n}$ - the average daily number of vehicles for traffic class $n$ (vehicles/day); $e_{n}-$ unit factor for traffic class $n$.

Summing up the three grades assigned to the three goals, we get a global ranking for that section. Since the determination of the ratio between the individual goals goes beyond the technical tasks, we have tried several different proportions during the examination. In the final version, with the intention of emphasizing the state of the pavement, the following weighting was included (Eqn (5)):

$$
G=0.6 G_{c}+0.2 G_{e}+0.2 G_{t} .
$$

Based on the rankings assigned to each section, we recommend the highest scores for optimal use of available budgets. Given that the ranked intervention project list is "just" a decision support document, it only deals with technical-economic aspects. It is advisable to leave the consideration of further considerations to the decision makers.

\section{Lifetime cost based ranking}

In the medium term, our goal is to develop lifetime costbased ranking alongside the current ranking method. It is recommended to define the "lifetime costs with intervention": $L C C_{i}$. To do this, we first need to define a "maintenance calendar" based on existing state parameter degradation curves. The maintenance calendar includes the maintenance tasks expected in each year and their expected cost throughout the lifecycle of the road section. It is also necessary to determine the status-dependent road user costs and the annual discounter.

Similarly, lifetime costs without intervention should be determined: $L C C_{w i}$. The planned ranking of intervention projects is based on the ratio of $L C C_{i}$ and $L C C_{w i}$. The estimated cost of intervention and the amount of money available to Budapest Roads to renovate the roads determines what part of intervention list is feasible:

$$
\begin{aligned}
L C C_{i} & =C_{\dot{e}}+\sum_{i=1}^{n}\left[\left(C_{m i}+C_{o i}+C_{u i}\right)(1-d)^{i-1}\right] ; \\
L C C_{w i} & =\sum_{i=1}^{n}\left[\left(C_{m w i}+C_{o w i}+C_{u w i}\right)(1-d)^{i-1}\right],
\end{aligned}
$$

where: $L C C_{w i}$ - lifetime costs without intervention (HUF); $L C C_{i}$ - lifetime costs with intervention (HUF); $C_{\dot{e}}-$ intervention cost in the first year (HUF); $i$ - the number of years of attention (between 1 to $n$ ); $n$ - lifetime of the testing (year, typically 20 or 25); $C_{m i}$ - maintenance cost with intervention in year $i$ (HUF); $C_{o i}$ - operating cost with intervention in year $i$ (HUF); $C_{u i}$ - road user cost with intervention in year $i$ (HUF); $C_{m w i}$ - maintenance cost without intervention in year $i$ (HUF); $C_{\text {owi }}$ - operating cost without intervention in year $i$ (HUF); $C_{u w i}$ - road user cost without intervention in year $i$ (HUF); $d$ - discount factor (typically 0.03-0.05).

\section{Conclusions}

The PMS of the capital of Hungary presented in this article is unique in Hungary but may be because of our data collecting and evaluating method also very rare in Europe. It is very important to underline, that after the data collecting and evaluation process our PMS follows an multi variable optimization methods to define the proper rehabilitation technique, and moreover the summarized network's level investment list and the ranking of the rehabilitation projects. Furthermore we need to underline that the PMS system presented in this paper may need further refinement for example regarding carrying capacity results and road structure thickness. We suggest that in the close 
future we have to introduce another variable in our optimization methods. With the lifetime cost based ranking (see Section 5) we should get more realistic picture in our PMS. There is further scientific details that can be studied regarding strengthening types, and also it would be nice to consider the sizing method based on asphalt degradation (E modulus), too. It would be also important step to differentiate the degradation curbs based on road structure types. In general it is obviously traceable based on the presented PMS system we can immediate determine the scale of the necessary cost allocation - 250-300 billion HUF for the pavement rehabilitation for capital city like Budapest.

\section{Acknowledgements}

The authors express grateful thanks to Márk Németh, Dr Kálmán Ambrus, Gyula Fekete, Lóránt Csiszér, Dénes Kovács, József Orbán, Réka Tihanyi, Flóra Arnóczki, Zsolt Dégen for their very helpful advices, suggestions. With their remarks, the quality of the publication was significantly increased. The authors are especially grateful to Ákos Dávid for the improvement and devotional help of the manuscript. Also grateful thanks are expressed to OTKA for the support (K119440).

\section{Funding}

The case report was supported by the Municipality of Budapest and Budapest Roads.

\section{Author contributions}

Gábor Pusztai was involved in defining the process and collecting the basic data. János Logó helped to define the optimization methods of the PMS. Kornél Almássy defined the strategic directions and László Gáspár was responsible for the professional control of the results. Kornél Almássy wrote the first draft of the article.

\section{Disclosure statement}

The authors declare that the research was conducted in the absence of any commercial or financial relationships that could be construed as a potential conflict of interest.

\section{References}

Almássy, G., \& Németh, M. (2014). Roughness measurement process according to RODIS pointcloud. Asphalt Magazine, 2, 31-39.

Almássy, K., Dávid, Á., \& Pusztai, G. (2018). Results of the capital's pavement management system. Útügyi Lapok, 11.

Ambrus, K. (2015). Development of the pavement management system in Budapest. Budapest: Budapest Roads.

Bakó, A., Gáspár, L., \& Kovács, D. (2012). Burkolatgazdálkodási modellek a fővárosi főutakhoz. Közlekedéstudományi Szemle, 62(6), 38-49 (in Hungarian).
BKK Közút Zrt. (2015). Project report on adapting the PMS model of KTI to the system of BKK Közút, and defining directions for improvement.

Chang, J.-R., Su, Y.-S., Huang, T.-C., Kang, S.-C., \& Hsieh, S.-H. (2009). Measurement of the International Roughness Index (IRI) using an autonomous robot (P3-AT). In 26th International Symposium on Automation and Robotics in Construction (pp. 325-331). Austin, Texas, USA. https://doi.org/10.22260/ISARC2009/0052

Chen, L., \& Bai, Q. (2019). Optimization in decision making in infrastructure asset management: A review. Applied Sciences, 9(7), 1380. https://doi.org/10.3390/app9071380

Gáspár, L. (2003). Útgazdálkodás. Budapest: Akadémiai Kiadó (in Hungarian).

Gáspár, L. (2017). Management aspects of road pavement rehabilitation. Gradevinar, 69, 31-40. https://doi.org/10.14256/JCE.1629.2016

Hillier, F. S., \& Lieberman, G. J. (2005). Introduction to operations research (8th ed.). New York: Elizabeth A. Jones.

Lefsky, M. A., Cohen, W., Acker, S., Parker, G. G., Spies, T., \& Harding, D. (1999). Lidar remote sensing of the canopy structure and biophysical properties of douglas-fir western hemlock forests. Remote Sensing of Environment, 70(3), 339-361. https://doi.org/10.1016/S0034-4257(99)00052-8

Lógó, J. (1988). Design of bar structures by multicriteria optimization (Doctoral Thesis). Technical University of Budapest.

Lógó, J., \& Kaliszky, S. (2003). Application of multicriteria optimization in layout optimization of structures. In Proceedings of the International Conference on Metal Structures (ICMS-03) (pp. 271-276). Rotterdam, Holland.

Lógó, J., \& Vásárhelyi, A. (1988). Pareto optima of reinforced concrete frames. Periodica Polytechnica - Civil Engineering, 32(1-2), 87-96.

Lógó, J., Kacianauskas, R., Bernau, H., \& Vásárhelyi, A. (1989). Mnogokriterialnaja optimizacija zselezobetonnyh ram. Litovskij Mehaniceskij Sbornik, 31, 33-42 (in Russian).

Markó, G., Primusz, P., \& Péterfalvi, J. (2013). Measuring the bearing capacity of forest roads with an improved Benkelman beam apparatus. Acta Silvatica et Lignaria Hungarica, 9(1), 97-109. https://doi.org/10.2478/aslh-2013-0008

Markó, G., Primusz, P., Péterfalvi, J., \& Tóth, C. (2015). Effect of pavement stiffness on the shape of deflection bowl. Acta Silvatica et Lignaria Hungarica, 11(1), 39-54. https://doi.org/10.1515/aslh-2015-0003

Németh, M., \& Pusztai, G. (2016). Data collecting and condition evaluation in Budapest's roads. Asphalt Magazine, 1, 47-54.

Rusu, L., Taut, D. A. S., \& Jecan, S. (2015). An integrated solution for pavement management and monitoring systems. Procedia Economics and Finance, 27, 14-21. https://doi.org/10.1016/S2212-5671(15)00966-1

Sun, Z., Xu, Y., Hoegner, L., \& Stilla, U. (2018). Classification of MLS point clouds in urban scenes using detrened geometric features from Supervoxel-based local contexts. Annuals of the Photogrammetry, Remote Sensing and Spatial Information Sciences, 4(2), 271-278. https://doi.org/10.5194/isprs-annals-IV-2-271-2018

Vittilo, N. (2013). Pavement management system overview. Retrieved from https:/www.state.nj.us/transportation/eng/pavement/pdf/PMSOverviews0709.pdf

Vosselman, G., \& Maas, H.-G. (2010). Airborne and terrestrial laser scanning. CRC Press. 